2010-03-01

\title{
Novel AC Side P\&O Maximum Power transfer control for Grid Connected Photovoltaic Systems
}

\author{
Mohamed Moin Hanif \\ Technological University Dublin, mohamed.hanif@tudublin.ie \\ Malabika Basu \\ Technological University Dublin, mbasu@tudublin.ie \\ Kevin Gaughan \\ Technological University Dublin, Kevin.Gaughan@tudublin.ie
}

Follow this and additional works at: https://arrow.tudublin.ie/engscheleart

Part of the Controls and Control Theory Commons, Electrical and Electronics Commons, and the Power and Energy Commons

\section{Recommended Citation}

M. Hanif, M. Basu and K. Gaughan "Novel AC side P\&O Maximum Power transfer control for Grid Connected Photovoltaic Systems”, ICREPQ 2010.

This Conference Paper is brought to you for free and open access by the School of Electrical and Electronic Engineering at ARROW@TU Dublin. It has been accepted for inclusion in Conference papers by an authorized administrator of ARROW@TU Dublin. For more information, please contact arrow.admin@tudublin.ie, aisling.coyne@tudublin.ie,gerard.connolly@tudublin.ie. Funder: Dublin Institute of Technology

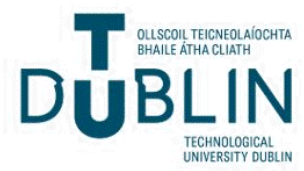




\title{
Novel AC Side P\&O Maximum Power transfer control for Grid Connected Photovoltaic Systems
}

\author{
M. Hanif, M. Basu and K. Gaughan
}

Department of Electrical Engineering Systems

Dublin Institute of Technology

Kevin Street, Dublin 8, Ireland

Phone/Fax number: 0035314022814,00353851195632 e-mail: mohamed.hanif@dit.ie, mbasu@ieee.org

\begin{abstract}
Grid connected Photovoltaic inverters can convert $\mathrm{PV}$ energy into electricity with very high efficiencies. Power from the PV panels fluctuates depending on various weather conditions. PV inverters usually include a maximum power point tracker (MPPT) to track this varying power, in order to transfer all the available power to the grid efficiently. Control of power transferred to the grid along with the MPPT plays a crucial role in determining the efficiency of a PV system.
\end{abstract}

This paper discusses about the basic power transfer theory between sources (PV and Grid) and focuses on the need of a DC-DC boost circuit, along with a DC-AC inverter to transfer maximum power from the PV to the grid. A commonly used approach for transferring the maximum power from the PV to the grid at all times will be briefed and a new approach proposed.

Now reference current calculation can work using a MasterSlave principle where the DC-DC converter and the inverter could act as the master or slave and vice versa, after the new proposed approach is introduced.

The new approach would not require any DC side measurements for MPP tracking making it a sensor less approach.

Comparative conclusion between ease of implementation and effectiveness of the above two approaches are given.

\section{Key words}

Maximum power transfer, Grid connected PV Inverter, Power transfer, AC side $\mathrm{P} \& \mathrm{O}$

\section{Introduction}

To understand the power flow from the PV source (PV Panel \& the inverter) to the Grid in a grid connected system the Power flow between two AC sources as shown in the system below is analyzed:

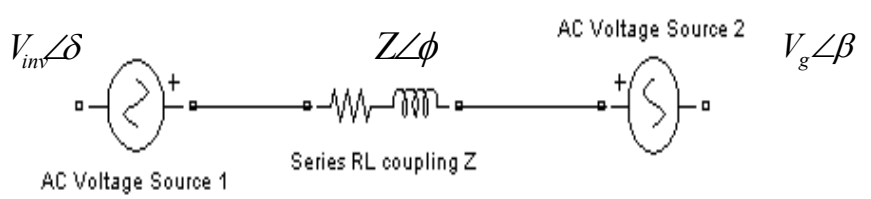

Figure 1: Power flow between two AC Sources
The diagram above shows two power source coupled with an impedance of $\mathrm{Z}=\mathrm{R}+\mathrm{jX}$ whose $|Z|=\sqrt{R^{2}+X^{2}}$

$\phi=\tan ^{-1}\left(\frac{X}{R}\right)$ and source 1 and source 2 represent the PV source and the Grid respectively.

Source 1 is identified with $V_{i n v} \angle \delta$ and Source 2 with $V_{g} \angle \beta$ where, $\mathrm{V}$ represents the rms voltage and the angles $\delta$ and $\beta$ represent the phase reference.

If power flows from source 1 to source 2 through the coupling $\mathrm{Z}$, the current flow I, can be defined as:

$I=\frac{V_{i n v} \angle \delta-V_{g} \angle \beta}{R+j X}=\frac{V_{i n v} \angle \delta-V_{g} \angle \beta}{Z \angle \phi}$

Using $S=V . I^{*}$ we get:

$$
\begin{aligned}
& S=V_{i n v} \angle \delta\left(\frac{V_{i n v} \angle \delta-V_{g} \angle \beta}{Z \angle \phi}\right)^{*} \\
& S=\frac{V_{i n v} V_{i n v} \angle(\delta-\delta)-V_{i n v} V_{g} \angle(\delta-\beta)}{Z \angle-\phi} \\
& S=\frac{V_{i n v}{ }^{2}}{Z} \angle \phi-\frac{V_{i n v} V_{g}}{Z} \angle \delta-\beta+\phi \\
& S=\frac{V_{i n v}{ }^{2}}{Z} \cos \phi+j \frac{V_{i n v}{ }^{2}}{Z} \sin \phi-\frac{V_{i n v} V_{g}}{Z} \cos (\delta-\beta+\phi) \\
& -j \frac{V_{i n v} V_{g}}{Z} \sin (\delta-\beta+\phi) \\
& S=\frac{V_{i n v}{ }^{2}}{Z} \cos \phi-\frac{V_{i n v} V_{g}}{Z} \cos (\delta-\beta+\phi) \\
& +j\left(\frac{V_{i n v}{ }^{2}}{Z} \sin \phi-\frac{V_{i n v} V_{g}}{Z} \sin (\delta-\beta+\phi)\right) \\
& \operatorname{Re}[S]=P=\frac{V_{i n v}{ }^{2}}{Z} \cos \phi-\frac{V_{i n v} V_{g}}{Z} \cos (\delta-\beta+\phi) \\
& \operatorname{Im}[S]=Q=\frac{V_{i n v}{ }^{2}}{Z} \sin \phi-\frac{V_{i n v} V_{g}}{Z} \sin (\delta-\beta+\phi)
\end{aligned}
$$


Real Power Flow

Now considering

$P=\frac{V_{i n v}^{2}}{Z} \cos \phi-\frac{V_{1 i n v} V_{g}}{Z} \cos (\delta-\beta+\phi)$

If the phase reference $\beta$, for Source 2 (Grid) is put to zero:

$P=\frac{V_{i n v}^{2}}{Z} \cos \phi-\frac{V_{i n v} V_{g}}{Z} \cos (\delta+\phi)$

And if we assume $\mathrm{R}$ is very small, only inductive coupling is used in $\mathrm{Z}$,

$$
\begin{aligned}
& R \approx 0, \phi \approx 90^{\circ} Z \approx X \\
& P=\frac{V_{i n v}^{2}}{X} \cos 90-\frac{V_{i n v} V_{g}}{X} \cos (\delta+90) \\
& P=\frac{V_{i n v} V_{g}}{X} \sin \delta
\end{aligned}
$$

\section{Reactive Power Flow}

Considering

$$
Q=\frac{V_{i n v}^{2}}{Z} \sin \phi-\frac{V_{i n v} V_{g}}{Z} \sin (\delta-\beta+\phi)
$$

And assuming phase reference $\beta=0, R \approx 0, \phi \approx 90^{\circ}$ and $Z \approx X$

We have

$Q=\frac{V_{i n v}{ }^{2}}{X}-\frac{V_{i n v} V_{g}}{X} \sin (\delta+90)$

$Q=\frac{V_{i n v}^{2}}{X}-\frac{V_{i n v} V_{g}}{X} \cos \delta$

$Q=\frac{V_{i n v}}{X}\left(V_{i n v}-V_{g} \cos \delta\right)$

Since $V_{g} \angle 0$ represents the Grid of $230 \angle 0$ (230V rms and 0 Phase reference) and $\mathrm{X}$ is of fixed value, using theory and the simulation results it was found that when $\mathrm{R}$ is kept close to 0 , the losses across $\mathrm{R}$ is very small, and the power transfer depends accordingly:

- Real power mainly depends on $\delta$

- Reactive power mainly depends on $V_{i n v}$ ( $\mathrm{rms}$ voltage of Source 1)

The above is also confirmed with the statement made in [1].

\section{Photovoltaic Maximum Power Point tracker}

Photovoltaic cells generate variable and low output voltage (current) depending on the insolation. Thus, they are unable to connect to utility directly. However, they can be interfaced and supply power to utility by means of power electronic converters [2].

PV panels are put together in series to achieve a high output voltage rather than in parallel to achieve a high output current. Having a large number of panels that can give a DC voltage required by the inverter system is always not feasible. Therefore usually a DC-DC Boost Circuit is employed to increase the voltage at the inverter DC Link; this is mainly done to achieve a $325 \mathrm{~V}$ pk-pk voltage at the AC output terminals. This $325 \mathrm{~V}$ pk is a nominal operating voltage for most of today's loads and a low voltage European grid network.

One other reason for using the DC-DC Boost circuit would be to transfer all the tracked power by the MPPT algorithm to the Grid in a Grid connected system. In other words the DC-DC Boost circuit is used to acquire the maximum power out of the PV panels at all times.

Maximum power point tracking is done using an algorithm (using P\&O method in this case) that perturbs the duty cycle of the DC-DC Boost Circuit (see figure 2 and 4) and observes the change in power. The duty cycle is then increased or decreased in the direction of increasing power [4].

According to equation $I=\frac{V_{i n v} \angle \delta-V_{g} \angle \beta}{Z \angle \phi}$, the inverter AC side current, I, will depend on $V_{i n v} \angle \delta$ since $V_{g} \& \mathrm{Z}$ are fixed in a grid connected system. $V_{i n v}$ and $\delta$ can be controlled according to the $\mathrm{I}_{\text {ref }}$ (inverter reference current) to deliver the available power into the grid.

The goal of this paper is to first discuss how $I_{\text {ref }}$ is achieved in the traditional power control mechanism used for grid connected PV systems and then discuss the new proposed approach. Finally both of these approaches will be comparatively interpreted in terms of ease of implementation and their effectiveness on a stable operation.

Commonly adopted method: Dc-dc boost circuit could be used to extract maximum power from the PV panel. Power at the DC side is measured and the duty cycle of the boost circuit is increased, power is measured again and duty cycle perturbed accordingly (see figure 2). This extracted power changes the DC link. The DC link controller uses the sensed DC Link voltage value and compares it to a reference value of $780 \mathrm{~V}$ (in this case) and changes the reference current (inverter side) $I_{\text {ref }}$ accordingly, which in turn regulates the PWM switches of the inverter. 
Here Boost circuit extracts the maximum power independently, while the dc link controller maintains the DC link voltage by controlling the inverter current $[1,3-$ 4].

Figure 2 shows the MPPT controller run at $50 \mathrm{~Hz}$ to track the power using measured DC values.

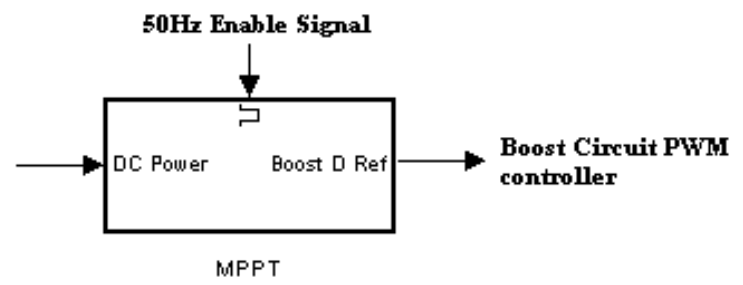

Figure 2: MPPT Controller for the common method

New method (Proposed method):

DC Power at the PV side has always been used for MPP tracking as discussed above, power at $\mathrm{AC}$ side has never been considered. In this paper, power (current) at AC side could be measured to track the MPP, and the proposed method takes advantage of this interesting concept which is discussed below.

A sketch of the I-V and P-V characteristic at the PV side and the inverter side is shown in figure 3.

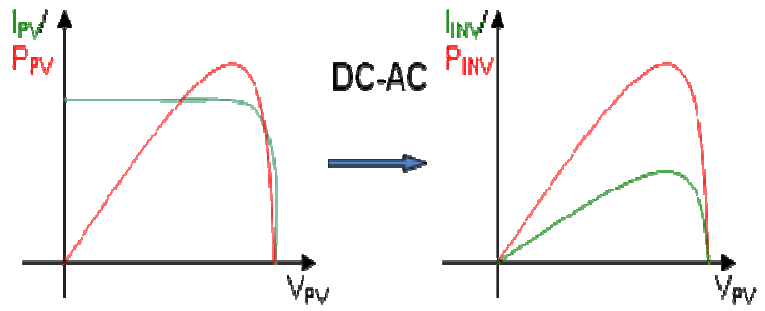

Figure 3: Sketch of I-V and P-V characteristic of a PV Panel and Inverter

From figure 3 it can be deduced that for a three phase inverter:

$$
\begin{gathered}
\mathrm{P}_{\mathrm{INV}}=\left(\mathrm{P}_{\mathrm{PV}}-\text { Losses }\right) \\
I_{I N V}=\frac{P_{I N V} / 3}{V_{g}}
\end{gathered}
$$

Where:

$\mathrm{P}_{\mathrm{INV}}$ is inverter output power

$\mathrm{P}_{\mathrm{PV}}$ is input $\mathrm{PV}$ power

$\mathrm{I}_{\mathrm{INV}}$ is inverter output current

$\mathrm{V}_{\mathrm{g}}$ is grid voltage

Left (PV side) of figure 3 shows the usual $\mathrm{I}_{\mathrm{PV}}-\mathrm{V}_{\mathrm{PV}}$ and $\mathrm{P}_{\mathrm{PV}}-\mathrm{V}_{\mathrm{PV}}$ characteristic of a PV Panel. This special power curve characteristic is utilised in the commonly used MPPT approach to extract the maximum power at the point when $\mathrm{dP} / \mathrm{dV}=0$. When looking at the $\mathrm{AC}$ side (inverter side) the $\mathrm{P}_{\mathrm{INV}}-\mathrm{V}_{\mathrm{PV}}$ and $\mathrm{I}_{\mathrm{INV}}-\mathrm{V}_{\mathrm{PV}}$ characteristic seem to be linearly related as shown on the right of figure 3. This special I-V characteristic at the AC side can now be used to track the MPP by measuring the output current of the PV inverter (since the output voltage, $\mathrm{V}_{\mathrm{g}}$, of the inverter is constant).

The new concept uses the same P\&O MPPT algorithm explained for the commonly used MPPT approach, except that it no longer measures the DC power $\left(\mathrm{I}_{\mathrm{dc}}\right.$ and $\mathrm{V}_{\mathrm{dc}}$ ) instead the $\mathrm{AC}$ current output is acquired to perturb the duty cycle of the Boost Circuit as shown on figure 4.

\section{Novel AC Side P\&O MPPT}

AC side current (inverter output) is measured and the duty cycle of the boost circuit is increased, current is measured again and duty cycle perturbed accordingly in the direction of increased power. This extracted power changes the DC link. The DC link controller uses the sensed DC Link voltage value and compares it to a reference value of $780 \mathrm{~V}$ (in this case) and changes the reference current (inverter side) $\mathrm{I}_{\text {ref }}$ accordingly, which in turn regulates the PWM switches of the inverter.

Here the inverter side current extracts the maximum power with the use of boost circuit, while the dc link controller maintains the DC link voltage by controlling the inverter current. The inverter side depends on the boost circuit to control the MPP.

This novel method brings about sensor less MPP tracking, as the AC side (injected) grid current is always measured in a grid connected system and not requiring any DC side measurements for MPP tracking.

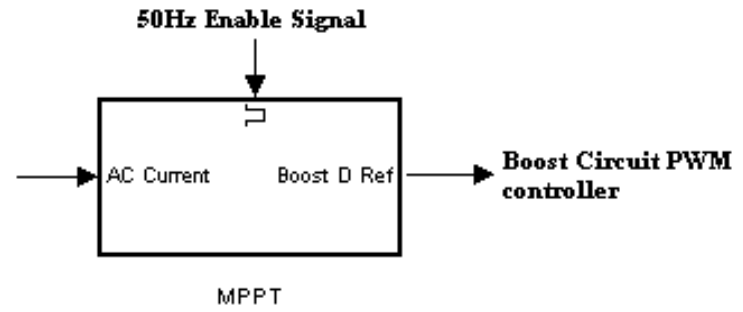

Figure 4: MPPT Controller for the novel approach

\section{Advantages of the new MPPT approach}

- Only one current sensor required to sense AC current Output for MPPT purpose in a balanced 3-Phase system.

- No DC sensors required, nor multiplier required to reveal power in digital control. This simplifies algorithm and computation.

- $\quad$ For a 3-Phase system, sensor of smaller rating is required compared to the common method as whole dc power is not measured, instead AC current (which reflects AC power) is sensed, which is quite small. 


\section{Simulation Results}

A PV curve of $3.45 \mathrm{~kW}$ peak is used to simulate the photovoltaic source. Both the commonly used MPPT approach and the novel approach are simulated in Simulink (tracking MPP at $50 \mathrm{~Hz}$ ) for a 3-Phase of photovoltaic grid connected inverter whose results are shown below on figures 5 and 7 respectively.

Inverter $\mathrm{V}_{\mathrm{dc}}$ Link controller, controls the $\mathrm{I}_{\text {ref }}$ to keep the capacitor voltage $\left(\mathrm{V}_{\text {cap }}\right)$ to $780 \mathrm{~V}$ as close as possible as shown in figure 5 .

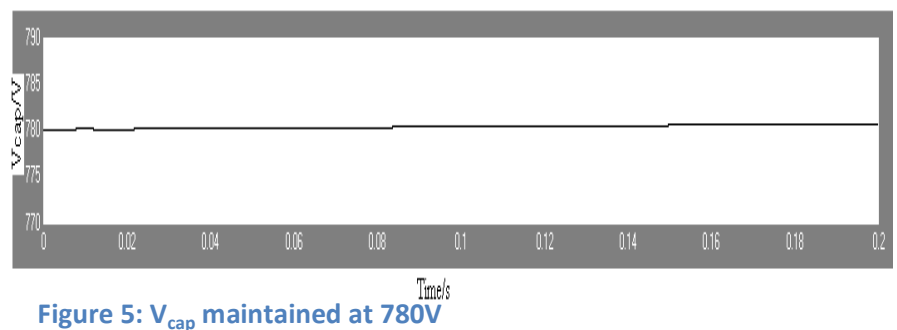

Figure 6 and 7 show the power extracted in the simulation. DC power calculated in figure 6 is used for MPP tracking, while DC power in figure 7 is just calculated to show that the novel approach extracts maximum power.

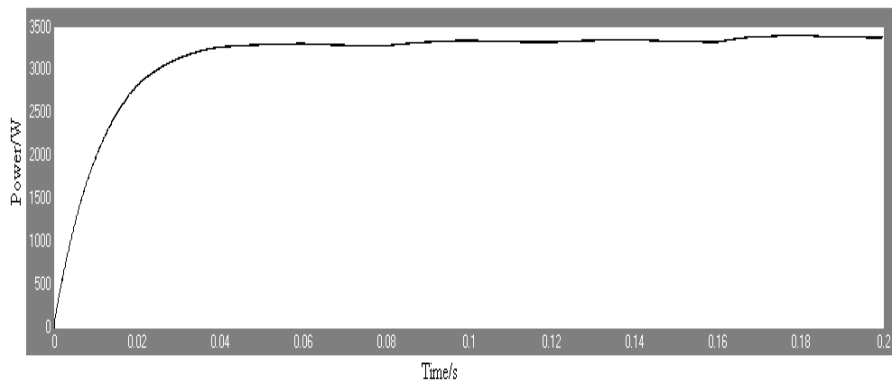

Figure 6: Power from PV tracked using the MPPT algorithm using the commonly used approach.

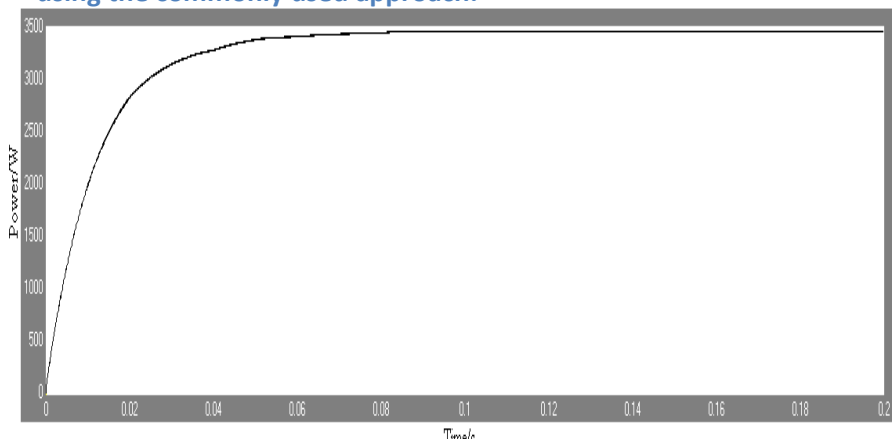

Timel's

Figure 7: Power from PV calculated to show the tracked MPP using the novel approach.

\section{Conclusion}

The paper discusses the need for a boost circuit to increase the voltage level and MPP tracking. It also discusses about the common method for MPPT and then proposes a new AC side $\mathrm{P} \& \mathrm{O}$ approach.
The new proposed method brings about a master-slave principle approach, where the Inverter and the Boost circuit are looked at as two different controlling stages. One of them can act as the Master while the other as a slave. Both of them can be used vice versa to control the overall transfer of maximum power to the Grid from the PV source.

Simulation results for both the common and novel approach show the working model of the system.

The new proposed approach uses only AC side grid current for MPPT(grid injected current is normally sensed in a grid connected system) and not requiring any DC side measurements making the approach a sensor less MPP tracking approach. Furthermore no compromises are made in the power tracking capability (compare figure 6 and 7) and serving some further advantages as mentioned earlier.

This new AC Side P\&O MPPT approach is quite a promising MPPT technique without requiring any DC measurements and works well delivering the maximum power available at the PV Source under different solar insolation levels.

\section{References}

[1] T. Kerekes, R. Teodorescu, M. Liserre, R. Mastromauro and A. Dell'Aquila, "MPPT algorithm for voltage controlled PV inverters" OPTIM 2008, 11th International Conference on Conference, on page(s): 427432, 22-24 May 2008

[2] M. Prodanovic, T. C. Green, "Control and Filter Design of Three-Phase Inverters for High Power Quality Grid Connection," IEEE Trans on Power Electronics, Vol.8, No.1, pp. 373-380, January 2003

[3] Luís G.B. Rolim, "Novel Control Stratergy for GridConnected DC-AC Converters with Load Power Factor and MPPT Control"

$\underline{\text { http://www.solar.coppe.ufrj.br/rolim.html }}$

[4] Jaen, C., et al. "Overview of maximum power point tracking control techniques used in photovoltaic systems." in Electronics, Circuits and Systems, ICECS 15th IEEE International Conference, 2008

[5] Rahim, N.A., J. Selvaraj, and Krismadinata. "Hysteresis Current Control and Sensor-less MPPT for Grid-Connected Photovoltaic Systems." in Industrial Electronics, 2007. ISIE 2007. IEEE International Symposium on. 2007 